\title{
Opportunities and Challenges of Peri-Urban Agriculture on the Fringes of the Metropolis of Rabat, Morocco
}

\author{
Fatiha Hakimi*, Mohamed Brech \\ Department of Production, Protection and Plant Biotechnology, Hassan II Institute of Agronomy and Veterinary Medicine, Rabat, \\ Morocco.
}

\begin{abstract}
How to cite this paper: Fatiha Hakimi, Mohamed Brech. (2021) Opportunities and Challenges of Peri-Urban Agriculture on the Fringes of the Metropolis of Rabat, Morocco. International Journal of Food Science and Agriculture, 5(2), 269-274. DOI: $10.26855 / \mathrm{ijfsa} 2021.06 .009$
\end{abstract}

Received: March 26, 2021

Accepted: April 20, 2021

Published: April 28, 2021

*Corresponding author: Fatiha Hakimi, Department of Production, Protection and Plant Biotechnology, Hassan II Institute of Agronomy and Veterinary Medicine, Rabat, Morocco.

Email: hakimi.fatiha@gmail.com

\begin{abstract}
The current study was aimed to assess practices, roles and challenges of peri-urban agriculture in Rabat Metropolis. Through purposive and stratified random sampling methods 50 respondents were selected. To achieve the objectives of this study, both qualitative and quantitative methods of data analysis were used. Data collection from farmers was based on field observation, interviews and field surveys. Descriptive statistics such as frequency distribution, Chi-square test, tests of normality and homogeneity of variances and Principal Component Analysis (PCA), were used. According to the major findings of the study, the major types of peri-urban farming practices in the study area includes: horticulture or production of fruits and vegetables, crop farming and some livestock rearing such as beef farming, sheep farming and poultry farming. The survey result reveals that there are various significances of PUA in the study area: it contributes to the economic development of the metropolis as it generates income for farmers, creates employment, contributes to food supply and enhances economic use of land and environmental beatification of the city. In the Metropolis of Rabat, PUA faces several constraints: legal constraints mainly the absence of laws regulating this activity and the obligation of some farmers in the peri-urban area to pay housing taxes. It is also subject to many technical constraints such as insufficient workforce and high labor costs, difficult access to irrigation water, lack of training and technical supervision and support from the concerned body. Finally, recommendations and suggestions have been forwarded based on the findings of the study.
\end{abstract}

\section{Keywords}

Peri-Urban Agriculture, Farming Practices, Livestock, Rabat, Morocco

\section{Introduction}

Peri-Urban agriculture can be briefly defined as all agricultural activities practiced on the outskirts of cities, including the activities of supplying, processing and marketing inputs and services [1]. The Food and Agriculture Organization (FAO) has assigned the acronym PUA (Peri-Urban Agriculture), to "peri-urban agriculture" designating the agriculture which develops in the zones surrounding the cities [2-3].

Characterized by its multifunctionality, Peri-Urban agriculture offers multiple advantages and services. It has been found to play an important role in many cities around the world [4], though it is often under-reported. It represents an important issue to meet the food needs of the cities; it participates in the generation of direct and indirect income, in the reduction of unemployment and the improvement of the living environment in urban spaces $[4,5,6,7,8,9]$.

Interest in urban agriculture as a policy tool has considerably increased in recent years due to two global demo- 
graphic milestones. In 2008, the world's urban population exceeded that of the rural for the first time in history [10] and in the late 2019, global population surpassed seven billion [11]. This trend is expected to continue and eventually peak in the 2050s at approximately eleven billion, with 7 billion living in cities [12]. The Global South will absorb 90\% of future urban population growth, notably in Asia and Africa. Annual rates of population increase of $5 \%$ are not an exception in the cities of these regions, meaning that the population doubles within approximately 14 years. Urban population growth between 2000 and 2020 in developing countries was 11.7 percent, 2 times higher than the rate of growth recorded in developed countries; in the least developed countries, it was 7.6 percent [13]. This growth occurs against a backdrop of volatile food prices and increasing food insecurity, with over 821 million people globally classified as malnourished; critically, a growing proportion of this number now occurs in urbanized areas [14].

These developments raise serious global, regional, and local challenges for employment, education, social cohesion, urban development, the environment, and food security.

In this situation, local provision of food, medicines, fibers and timber is a sheer necessity for the survival of many. Moreover, agricultural land can provide environmental, social and economic benefits such as generating fresh air that cools hot inner cities, offering places for recreation as well as opportunities for the generation of income and entrepreneurial activities in a mostly informal economy. However, the pressures of urban growth make it difficult to conserve farmland; but what is perhaps more problematic is that decision-makers and planners apparently still fail to recognize its value [15].

In Morocco, the percentage of urban population increased from 43\% to 55\% between 1982 and 2004 [16] and will probably reach $70 \%$ in 2050 . This urbanization is increasing mainly at the expense of lowland areas with high agricultural potential already irrigated or easily irrigable, phenomenon observable in most of the coastal plains of Morocco but also in the other countries around the Mediterranean.

The annual agricultural area consumed in Morocco by the different forms of urbanization is estimated at 4,000 hectares, 2/3 of which for real estate operations [17], despite the town planning law 12/90 advocating the principle of the preservation of highly productive agricultural land, and its translation into local planning and urbanism documents.

Like most major cities in the world, the metropolis of Rabat embodies the three challenges: urbanization, population growth and food security. Over the past 20 years, the metropolis has experienced significant urbanization during the 2000-2020 period to the detriment of rural/agricultural space. This phenomenon is mainly attributed to the demographic growth of the urban population of the Rabat-Salé-Kénitra region and to the rural exodus.

Few systematic studies have been carried out on peri-urban agriculture in Rabat and in Morocco in general. However, the continued growth of the metropolis indicates that a broader and more systematic understanding of the PUA is necessary to determine its importance and to help determine the best way to develop this type of agriculture in order to contribute to sustainability and food security for the city and the country in the future. This study represents the first known analysis of peri-urban agriculture on the fringes of the metropolis of Rabat with the aim of providing information on the importance of this activity and characterizing this type of agriculture. It will help also identify the various problems and challenges constituting an obstacle to the development of this sector.

\section{Methods}

\subsection{Study area description}

The region of Rabat-Salé-Kénitra, including the capital of the kingdom, is one of the 12 regions of Morocco, created by the new territorial division of the regions in 2015.

It is the result of the fusion of the ex-region of Rabat-Salé-Zemmour-Zaer and the ex-region of Gharb-Chrarda-Beni-Hssein. It is bounded to the north by the region of Tanger-Tetouant-Al Hoceima, to the southeast by the region of Fès-Meknès and to the south by the two regions of Casablanca-Settat and Beni-Mellal-Khénifra and to the west by the Atlantic Ocean [10] (Figure 1).

The area of Rabat is $118 \mathrm{~km}^{2}$. The peri-urban area includes two prefectures and one province; the prefecture of Salé $\left(672 \mathrm{~km}^{2}\right)$, the prefecture of Skhirate-Témara $\left(485 \mathrm{~km}^{2}\right)$ and the province of Khémisset $\left(8,305 \mathrm{~km}^{2}\right)$ [18].

It has a Mediterranean climate with a cold and rainy winter and average temperatures ranging between 0 and $5{ }^{\circ} \mathrm{C}$ at night and can reach $17^{\circ} \mathrm{C}$ during the day. Summer has an oceanic climate with nights refreshed by the humidity coming from the ocean and days temperature around $30^{\circ} \mathrm{C}$. Exceptionally in spring or summer and during 3 or 4 days, the "Chergui" coming from the desert can raise temperatures up to $40^{\circ} \mathrm{C}$.

\subsection{Choice of the study area}

The study area was delimited to a radius of $40 \mathrm{~km}$ from the urban core of the city of Rabat in order to remain within the peri-urban perimeter while ensuring the presence of farms with the majority of existing speculations in the region (Figure 2). 


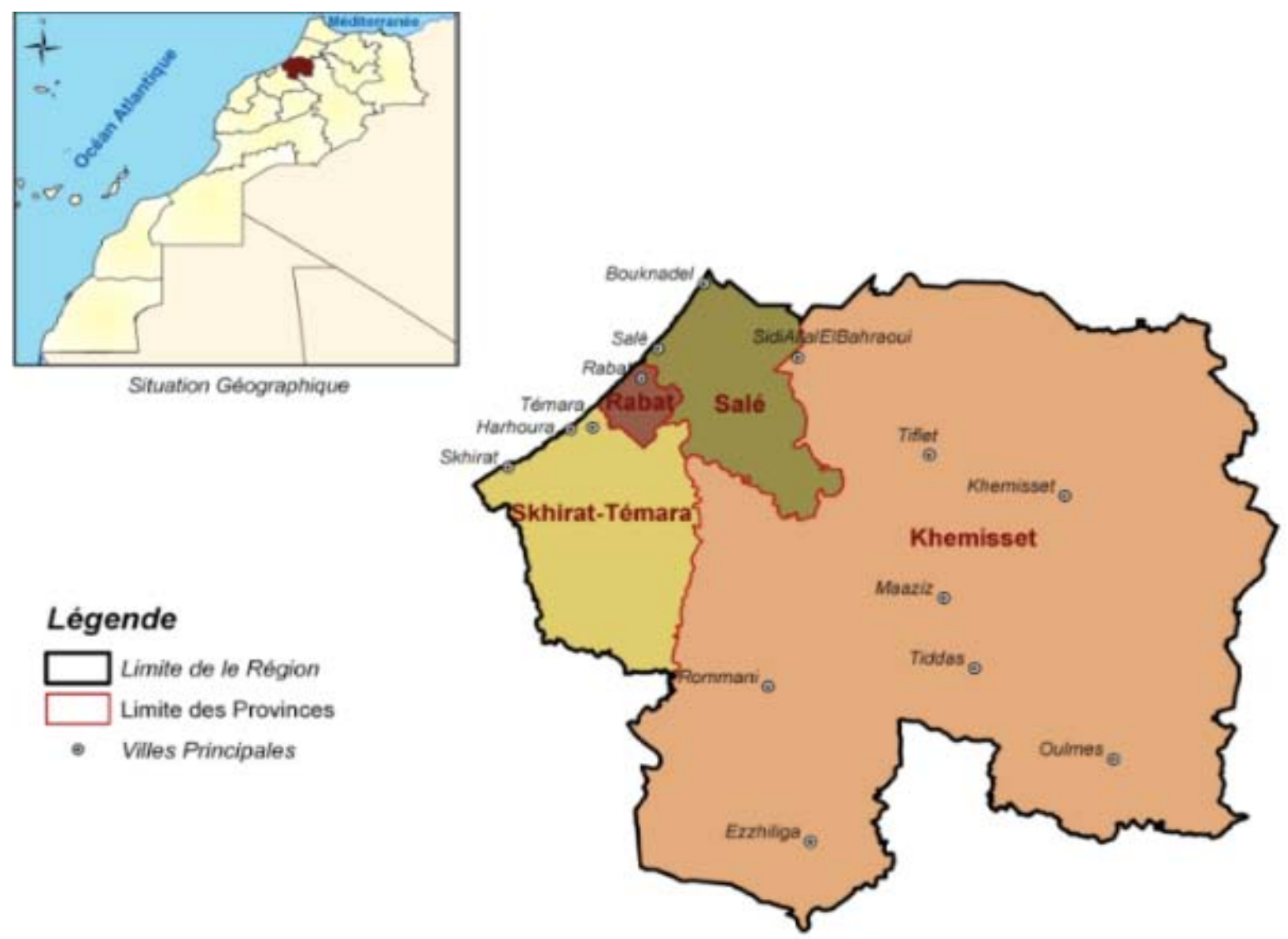

Figure 1. Map of Morocco showing the location of the region of Rabat-Salé-Kénitra.

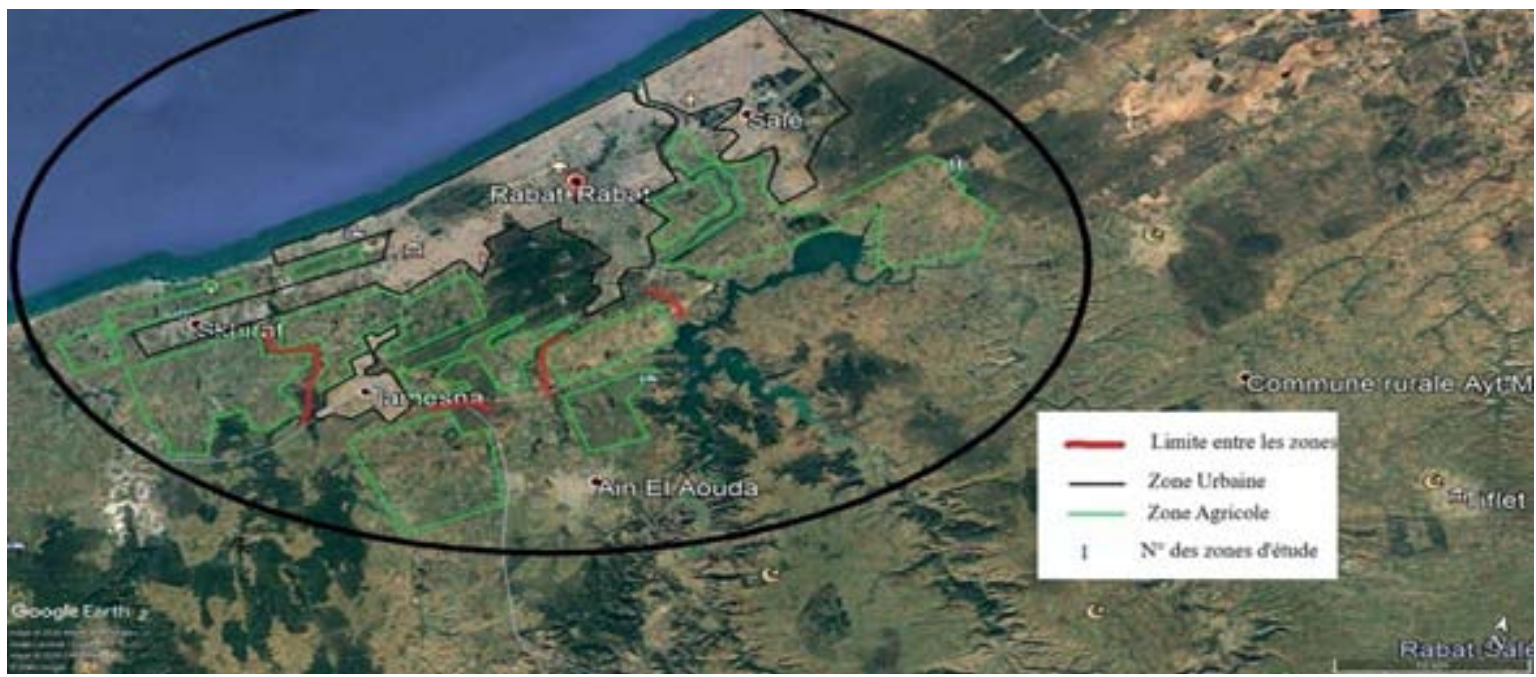

Figure 2. Delimitation map of the study area (Google Earth April 2020).

\subsection{Sampling technique and sample size}

The choice of farms was made according to several criteria:

- their location in relation to the city;

- the dynamism and willingness of farmers to participate in surveys;

- the main crop, to cover as many crops as possible and illustrate the diversity of products cultivated by the greatest number of farmers.

The choice and identification of these farms was made beforehand by several field surveys. Thus, a sample of 50 
farms was chosen to collect representative data of the region.

\subsection{Nature and sources of data}

The nature of the data was qualitative and quantitative. Both primary and secondary data sources were used. The primary sources of data for this study were collected from sample households that practice peri-urban agriculture. The secondary sources of data were collected from various published and unpublished documents of the regional agriculture department office and public administration offices of Rabat.

\subsection{Data collection tools}

Data collection from farmers was based on field observation, interviews and field surveys. For this, a questionnaire of a series of 83 questions was developed and administered to 50 farmers.

\subsection{Data analysis and interpretation techniques}

The collected raw data were systematically organized, summarized, processed and interpreted using appropriate data analysis techniques to make them meaningful and to draw sound conclusion based on the research findings. The data collected through questionnaire are quantitatively tabulated, interpreted and presented by using stastical methods such as frequency distribution, Chi-square test, Tests of normality and homogeneity of variances, means comparison test and Principal component analysis (PCA) were used for the analysis of the data collected. The analysis is made by using SPSS version 26 (Statistical Package of Social Sciences, V26.0) and Ms Excel.

\section{Results and discussion}

\subsection{Peri-urban farming practices in the Metropolis of Rabat}

Peri-urban agriculture appeared to be the main source of income for $78 \%$ of the households interviewed, which indicates its important role for urban livelihoods as well as for employment opportunities. According to a study carried out in Dar Es Salaam, Tanzania, peri-urban agriculture provided an estimated 20\% of all jobs in the town [19]. In Lomé, Togo, the mean monthly income of a market gardener amounted to that of a senior public servant [20], and in Nairobi, peri-urban agriculture used to provide the highest self-employment earnings in small-scale enterprises and the third highest earnings in all of urban Kenya [21].

In peri-urban areas of Rabat, the farmers conduct different types of agricultural practices in view of increasing their income through different ways.

As information obtained from the key informants and sample respondents, the most dominant speculation in the peri-urban area in the metropolis of Rabat is vegetable crops, with $56 \%$ of the respondents who practice vegetable crops. While arboriculture, field crops and fodder crops represent $44 \%$ of total food production.

With regard to the proportion of the destination of crops grown were by farmers. The dominance of crops destined for sale is clear. They represent $60 \%$ of the total sample. Results of the survey indicate that $28 \%$ of the surveyed population sells only a part of their production while the rest is intended for self-consumption. Food crops represent $12 \%$ and are mainly fodder crops intended for animal feed.

Both cash and food crops are mainly vegetable crops and cereals such as common wheat, potatoes, tomatoes, etc.

The survey result reveals also that livestock is a practice less regarded by farmers in the region: $54 \%$ of respondents do not practice livestock while $46 \%$ who do it have only a small herd.

In general, the most common types of livestock farming practice in the study area includes: beef farming, sheep farming and poultry farming practices. Such types of farming activities are kept in both peri-urban and rural areas of the country for various uses including milk and milk products, meat, eggs, food, cash and various cultural uses [22].

\subsection{The potential and significance of peri-urban agriculture in the Rabat metropolis}

Economic profitability is a determining factor in characterizing the importance of peri-urban agriculture. The survey result reveals that there are various significances of peri-urban farming in the study area: it contributes to the economic development of the metropolis as it generates income for farmers, creates employment opportunities, contributes to food supply and enhances economic use of land and environmental beatification of the city. Jouve and Padilla [23], who demonstrated that the peri-urban agriculture offers several functions such as food, socio-economic, environmental and territorial services, confirmed the same results.

\subsection{Challenges of peri-urban agriculture in the Rabat metropolis}

According to the major findings of the study, peri-urban agriculture in the metropolis of Rabat faces several constraints such as: legal constraints mainly related to the absence of laws regulating this activity at the national level and 
the obligation of some operators in the peri-urban area to pay housing tax. It is also subject to a certain number of technical constraints: insufficient workforce and high labor costs, difficult access to irrigation water and lack of technical supervision and support from the concerned body and lack of training.

\section{Conclusion}

Peri-urban agriculture is indeed multifunctional, ensuring both a food production function (fruits and vegetables) intended for sale in the metropolis of Rabat, a socio-economic function and an environmental function. It allows the creation of employment for the benefit of the region's youth and the generation of income for farmers. According to the major findings of the study, the major types of peri-urban farming practices in the study area includes: horticulture or production of fruits and vegetables, crop farming and livestock rearing such as beef farming, sheep farming as well as poultry farming. Peri-urban agriculture contributes also to the recycling of livestock products and the development of open spaces thus contributing to the creation of a beautiful landscape for urbanites.

The future of peri-urban agriculture in Morocco remains unclear and depends essentially on the government's desire to keep cultivable agricultural areas near Moroccan cities, to establish regulations to supervise it and to integrate this activity into the schemes of urban development and planning.

\section{Recommendations}

The main recommendations based on the finding of this study are:

- Strengthening the supervision and training of farmers for a sustainable use of peri-urban agricultural space.

- The integration of peri-urban agriculture into urban development plans as well as the legalization and official recognition of this activity.

- The development of projects for the sustainable and environmental management of these peri-urban agricultural areas through the strengthening of supervision and training initiatives for the benefit of peri-urban farmers and the encouragement of the creation of associative networks bringing together all the actors and professionals.

Finally, it is researcher's conviction that the above-mentioned recommendations if implemented will combat the challenges of peri-urban agriculture in Morocco if not fully, at least partially.

\section{References}

[1] Sawio, C. (1998). Managing urban agriculture in Dar Es Salaam. Cities Feeding People Report 20, IDRC, Ottawa.

[2] FAO (Food and Agriculture Organization of the United Nations). (2001). Urban and Peri-Urban Agriculture. A briefing guide for the successful implementation of Urban and Peri-urban Agriculture in Developing Countries and Countries of Transition. Rome, FAO.

[3] Nugent, R. (2000). The impact of urban agriculture on the household and local economies. Growing Cities, Growing Food: Urban Agriculture on the Policy Agenda.

[4] De Bon, H., Parrot, L., Moustier, P. (2010). Sustainable Urban Agriculture in Developing Countries: A Review. Agronomy for Sustainable Development, 30(1): 21- 32.

[5] Aubry, C., Ramamonjisoa, J., Dabat, M. H., Rakotoarisoa, J., Rakotondraibe, J., Rabeharisoa, L. (2012). Urban Agriculture and Land Use in Cities: An Approach with the Multifunctionality and Sustainability Concepts in the Case of Antananarivo (Madagascar). Land Use Policy, 29(2): 429-439.

[6] Bunwaree, S. (2000). Cités horticoles en sursis ? L'agriculture urbaine dans les grandes Niayes au Sénégal. Sous la direction de Safiétou Touré Fall et Abdou Salam Fall, CRDI, 2001, ISBN 0-88936-936-4, Bulletin de l'APAD 20: 120.

[7] De Zeeuw, H., Van Veenhuizen, R., Dubbeling, M. (2011). The Role of Urban Agriculture in Building Resilient Cities in Developing Countries. Journal of Agricultural Science, 149(S1): 153-163.

[8] Dubbeling, M., De Zeeuw, H., Van Veenhuizen, R. (2010). Cities, Poverty and Food: Multistakeholder Policy and Planning in Urban Agriculture. Rugby, UK: Practical Action Publishing.

[9] Zasada, I. (2011). "Multifunctional Peri-urban Agriculture-A Review of Societal Demands and the Provision of Goods and Services by Farming.” Land Use Policy, 28(4): 639-648.

[10] UNDESA (United Nations Department of Economic and Social Affairs). (2010). World urbanization prospects: the 2009 revision. File 17a: Urban population (thousands), Number of cities and percentage of urban population by size class of urban settlement, major area, region and country, 1950-2025. Pop/db/wup/rev. 2009/2/f17a. New York. https://www.ipcc.ch/apps/njlite/ar5wg2/njlite_download2.php?id=10148.

[11] UNFPA (United Nations Population Fund). (2020). State of the World Population: Unleashing the Potential of Urban Growth. New York: UNFPA. https://www.unfpa.org/fr/data/world-population-dashboard.

[12] UN (United Nations, Department of Economic and Social Affairs, Population Division). (2018). World Urbanization Prospects: The 2018 Revision, Online Edition.

[13] UNDESA (United Nations Department of Economic and Social Affairs). (2020). File 2: Percentage of Population at Mid-Year Residing in Urban Areas by region, subregion and country, 1950-2050. https://population.un.org/wup/Download/. 
[14] FAO, FIDA, OMS, PAM, UNICEF. (2018). L’état de la sécurité alimentaire et de la nutrition dans le monde. Renforcer la résilience face aux changements climatiques pour la sécurité alimentaire et la nutrition. Rome, FAO.

[15] Pauleit, S., Pribadi, D. O., Abo El Wafa, H. (2019). Peri-urban agriculture: lessons learnt from Jakarta and Addis Ababa. Field Actions Science Reports. The Journal of Field Actions, (Special Issue 20): 18-25.

[16] HCP (Haut-Commissariat au plan). (2004). Recensement général de la population et de l'habitat 2004, Rabat, Maroc. http://www.hcp.ma/Recensement-general-de-la-population-et-de-l-habitat-2004_a633.html.

[17] Tarik, R. (2012). Environnement: l'urbanisation au détriment de l'agriculture, Le matin. https://lematin.ma/journal/2012/ Environnement_L-urbanisation-au-detriment-de-l-agriculture/162832.html.

[18] HCP (Haut-Commissariat au plan). (2016). Morocco in figures. https://www.hcp.ma/downloads/Maroc-en-chiffres_ t13053.html.

[19] Sawio, C. (1998). Managing urban agriculture in Dar Es Salaam. Cities Feeding People Report 20, IDRC, Ottawa.

[20] Abutiate, W. S. (1995). Urban and peri-urban horticultural activity in Ghana: an overview. In NRI, ed, Peri-Urban Interface Research: Workshop Proceedings, ODA, Kumasi, Ghana. Pp. 45-50.

[21] House, W., Ikiara, G., McCormick, D. (1993). Urban self-employment in Kenya: panacea or viable strategy? World Development, 21: 1205-1223.

[22] Powell, J. M., Pearson, R. A., Hiernaux, P. H. (2004). Crop-livestock interactions in the West African drylands. Agronomy Journal, 96(2): 469-483.

[23] Jouve, A. M., Padilla, M. (2007). Les agricultures périurbaines méditerranéennes à l'épreuve de la multifonctionnalité: comment fournir aux villes une nourriture et des paysages de qualité?. Cahiers Agricultures, 16(4): 311-317. 